\title{
PENYULUHAN DAN MUSYAWARAH DESA KHUSUS PENERIMA BANTUAN LANGSUNG TUNAI DANA DESA
}

\author{
Ramdhan Witarsa ${ }^{1}$, Mufarizuddin ${ }^{2}$, Sularno $^{3}$ \\ ${ }^{1,2}$ Program Studi PGSD, Fakultas Ilmu Pendidikan, Universitas Pahlawan Tuanku Tambusai \\ ${ }^{3}$ Kepala Desa Ridan Permai, Kecamatan Bangkinang Kota, Kabupaten Kampar \\ e-mail:drdadan19@gmail.com, zuddin.unimed@gmail.com
}

\begin{abstract}
Abstrak
Tujuan diadakannya penyuluhan dan musyawarah desa khusus penerima bantuan langsung tunai dana desa Ridan Permai ini dilakukan dengan tujuan untuk membangun kesepahaman antara pemerintah desa Ridan Permai dengan masyarakat penerima bantuan. Metode pengabdian masyarakat yang dilakukan adalah dengan pemberian penyuluhan mengenai informasi terkini tentang syarat-syarat dan ketentuan masyarakat penerima bantuan serta penyuluhan secara langsung mengenai peruntukan dan kegunaan bantuan langsung tunai tahun 2021 itu untuk apa saja. Penyuluhan ini berisi mengenai penjelasan-penjelasan secara umum tentang kriteria masyarakat penerima bantuan dan peruntukannya. Hasil yang didapatkan dari kegiatan penyuluhan ini adalah bertambahnya pengetahuan masyarakat mengenai syarat dan ketentuan penerima bantuan. Selama ini masyarakat hanya mendengar desas duses yang tidak jelas tentang syaratsyarat penerima bantuan yang tidak jelas sumbernya. Dari hasil pengabdian ini juga didapatkan semakin banyaknya masyarakat Desa Ridan Permai yang semakin peduli akan adanya penyuluhan dan musyawarah yang dilakukan secara berkala yang diselenggarakan oleh desa.
\end{abstract}

Kata kunci: Musyawarah Desa Khusus, Musdeskus, Penyuluhan, Penerima Bantuan, BLT, Dana Desa.

\begin{abstract}
The purpose of holding counseling and village meetings specifically for recipients of direct cash assistance from Ridan Permai village funds was carried out with the aim of building an understanding between the Ridan Permai village government and the beneficiary community. The community service method carried out is by providing counseling regarding the latest information on the terms and conditions of the recipient community as well as direct counseling regarding the designation and use of the 2021 direct cash assistance for anything. This counseling contains general explanations of the criteria for the recipient community and their allocation. The results obtained from this outreach activity are increasing public knowledge about the terms and conditions of the beneficiary. So far, the community has only heard rumors that are not clear about the terms of the recipients of aid whose sources are not clear. From the results of this service, it is also found that there are more and more people in Ridan Permai Village who are increasingly concerned about the existence of counseling and deliberations that are held regularly by the village.
\end{abstract}

Keywords: I Special Village Meetings, Musdeskus, Counseling, Beneficiaries, BLT, Village Funds.

\section{PENDAHULUAN}

Desa memiliki peluang untuk mengelola kepentingan dan kebutuhan masyarakat desa secara swadaya berdasarkan Undang-Undang No. 6 Tahun 2014. Dengan adanya pelimpahan wewenang yang cukup besar tersebut, desa berkewajiban untuk menerapkan prinsip akuntabilitas dalam tata pemerintahan desanya. Desa diharuskan mempertanggungjawabkan seluruh aktivitasnya kepada masyarakat desa dan Pemerintah Pusat (Lestari, D. et al., 2020). Dalam kaitannya dengan hal tersebut, maka kepala Desa menginisiasi suatu kegiatan yang dinamakan Penyuluhan dan Musyawarah Desa Khusus (Musdeskus) bagi penerima Bantuan Langsung Tunai (BLT) Dana Desa Tahun 2021, dalam hal ini tentu saja Desa Ridan Permai, Kabupaten Kampar, Provinsi Riau.

Dalam tahap perencanaan dan penganggaran, Pemerintah Desa diharuskan untuk meminta pertimbangan dari masyarakat desa yang diwakili oleh Badan Permusyawaratan Desa (BPD) 
sehingga rencana pembangunan desa dan pemberian BLT akan sesuai dengan kebutuhan dan tepat sasaran bagi masyarakat desa. Selain pertimbangan BPD, desa juga meminta masukan dari semua Rukun Warga (RW) yang ada dalam desa tersebut. Desa juga selalu mengundang dan melibatkan Badan Usaha Milik Desa (Bumdes), meskipun dalam beberapa pertemuan Bumbes ini tidak dapat hadir. Peran Bumdes dalam hal ini bisa memberikan masukan terhadap penguatan ekonomi desa yang bersangkutan (Ramadana, C. et al., 2010).

Salah satu desa yang berada di sekitar Universitas Pahlawan Tuanku Tambusai adalah desa Ridan Permai yang terletak di Kecamatan Bangkinang Kota, Kabupaten Kampar. Desa ini terdiri dari 8 RW dan 19 Rukun Tetangga (RT), dengan luas sebesar 2.800 ha. Desa Ridan Permai merupakan salah satu desa berprestasi dan meraih banyak penghargaan. Namun disisi lain, Desa Ridan Permai masih mengalami kesulitan dalam memetakan masyarakat yang tergolong layak sebagai penerima BLT. Hasil wawancara dengan pihak pemerintah Desa serta survei lapangan yang telah dilakukan, ditemukan bahwa masih terdapat masyarakat yang layak mendapatkan BLT, namun nyatanya tidak menerima BLT. Sebenarnya, kemampuan tata kelola pemerintah Desa dapat dikatakan cukup baik. Hal ini terbukti dengan data jumlah yang tidak puas akan kinerja desa bisa dihitung jari. Kendala yang ditemukan di lapangan adalah kurangnya koordinasi dan informasi yang didapatkan, serta keengganan beberapa masyarakat desa untuk hadir dalam kegiatan-kegiatan yang diselenggarakan desa. Belum adanya prosedur serta sarana dan prasarana dalam penyampaian informasi terkini merupakan salah satu penyebab timpangnya informasi tersebut. Hal ini menyebabkan proses pemberian BLT kepada masyarakat sasaran menjadi sedikit terkendala. Oleh karena itu, penyuluhan dan musdeskus yang berisi tentang pemberian pengetahuan dan informasi terkini tentang sasaran penerima BLT tahun 2021 sangat perlu dilakukan agar masyarakat memiliki pengetahuan dan informasi terkini mengenai syarat penerima dan peruntukkan BLT dana desa di tahun 2021 agar tidak termakan dengan isu-isu yang tidak jelas sumbernya.

Kegiatan pengabdian pada masyarakat yang pernah dilakukan sebelumnya adalah Penyuluhan Palawija Desa Ridan Permai untuk Eksistensi Keanekaragaman Hayati Sumber Pangan (Witarsa \& Mufarizuddin, 2020), Penyuluhan Palawija Desa Ridan Permai untuk Ketahanan Pangan Saat Pandemi Covid 19 (Sularno et al., 2020), dan Penyuluhan Asupan Nutrisi Kacang Kedelai terhadap Lemak Perut Masyarakat Desa Ridan Permai (Witarsa et al., 2020). Selama ini, apabila diperhatikan secara seksama, masyarakat Desa Ridan Permai yang selalu aktif dalam pertemuan-pertemuan desa orangnya itu-itu saja. Hanya satu atau dua orang saja wajah baru yang nampak masyarakat desa yang baru mulai aktif untuk hadir di pertemuanpertemua desa. Hal ini merupakan hal yang positif dikarenakan semakin bertambahnya anggota masyarakat Desa yang makin peduli terhadap desanya. Selain itu, dengan bertambahnya masyarakat desa yang mulai aktif hadir di pertemuan-pertemuan desa diharapkan semua informasi dari desa bisa sampai ke masyarakat lebih luas dan lebih akurat.

Pengabdian masyarakat melalui penyuluhan-penyuluhan dan musdeskus ini sangat penting dilakukan agar masyarakat mengetahui situasi dan kondisi yang terjadi di masyarakat. Desa Ridan Permai secara periodik cukup aktif melakukan pertemuan-pertemuan semacam ini, tergantung dengan tema dan kebutuhannya. Dengan kita turun langsung lapangan ke masyarakat, maka kita sebagai penyuluh akan mengetahui situasi dan kondisi yang sedang dialami masyarakat sehingga kita bisa berkontribusi didalamnya. Tujuan pengabdian masyarakat ini diungkapkan sebagai berikut:

1. Adanya perubahan sikap dan mindset kelompok masyarakat sasaran sesudah dilakukannya Penyuluhan dan Musdeskus tentang penerima BLT dana desa tahun 2021 di Desa Ridan Permai melalui Penyuluhan dan Pendampingan Berkelanjutan juga semakin bertambahnya anggota masyarakat di wilayah sekitar untuk aktif menghadiri pertemuan-pertemuan desa agar mendapat informasi terkini yang sumbernya akurat dan terpercaya.

2. Tersedianya bahan dan bantuan BLT dana desa untuk pembangunan masyarakat desa yang lebih banyak guna memenuhi kebutuhan dan permintaan masyarakat (Witarsa \& Mufarizuddin, 2020).

3. Semakin bertambahnya pengetahuan masyarakat akan pentingnya pertemuan-pertemuan, penyuluhan-penyuluhan, dan musdeskus yang berisi informasi-informasi terkini tentang BLT dana desa tahun 2021. 


\section{METODE}

Metode pengabdian masyarakat yang dilakukan adalah melalui pendidikan masyarakat berupa penyuluhan dan musyawarah yang bertujuan untuk meningkatkan pemahaman serta kesadaran masyarakat akan materi-materi yang diberikan oleh tim penyuluh (Chrisanto et al., 2020).

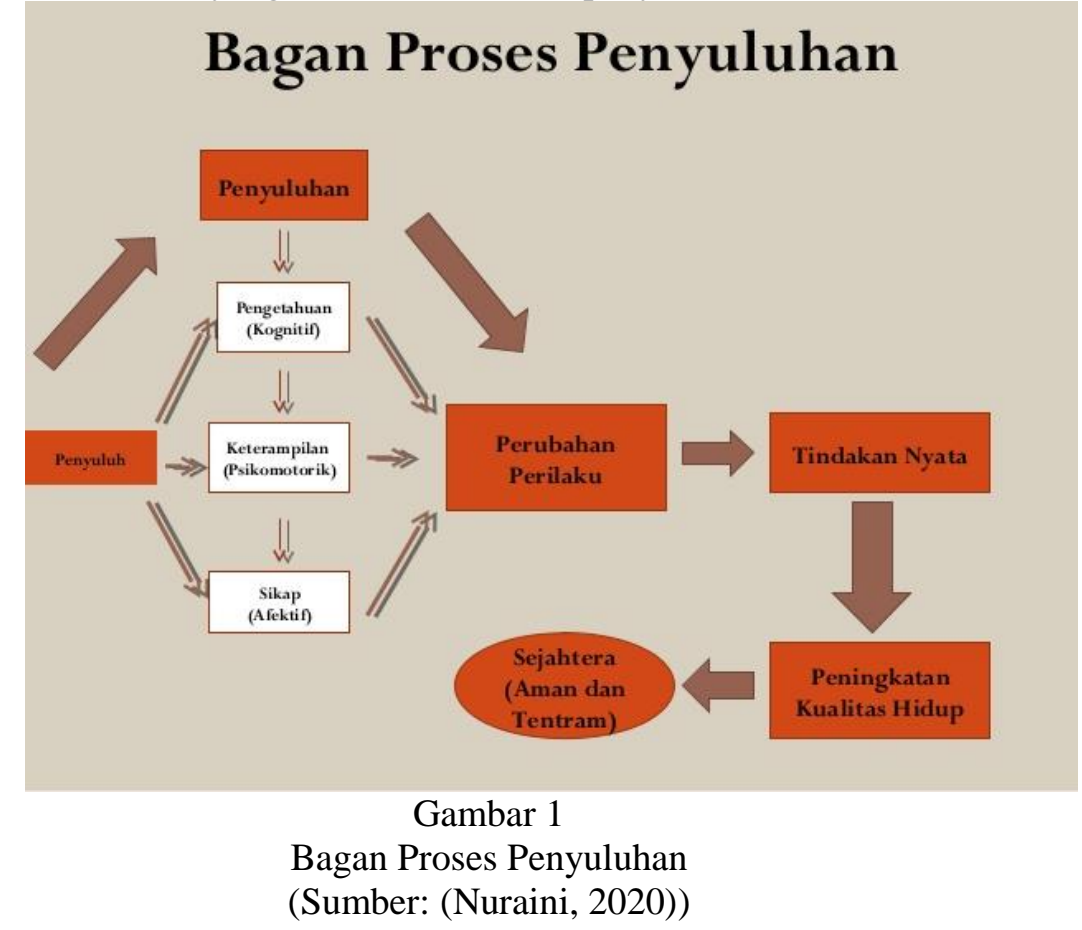

Berdasarkan bagan proses penyuluhan di atas, dapat dijelaskan bahwa Penyuluhan dan Musdeskus penerima BLT dana desa tahun 2021 ini dilakukan dengan tahapan sebagai berikut:

1. Tim penyuluh melakukan penyuluhan yang berdiri dari tiga aspek sebagai berikut:

a. Tim penyuluh memberikan pengetahuan akan pentingnya informasi terkini mengenai peruntukan dana desa dan serapannya bagi masyarakat yang benar-benar masuk kriteria penerima BLT tahun 2021.

b. Tim penyuluh kemudian memberikan kesempatan bagi anggota masyarakat untuk bertanya berdiskusi serta bermusyawarah mengenai hal-hal yang menjadi harapan dan kendala yang dihadapi.

c. Tim penyuluh memberikan contoh hasil sikap masyarakat yang sudah menggunakan dana BLT dari desa untuk sesuatu yang positif dan produktif.

2. Dari penyuluhan dan musdeskus yang telah dilakukan, tim penyuluh mengamati perubahan perilaku yang diharapkan, yaitu semakin pahamnya masyarakat akan BLT dana desa tahun 2021.

3. Tim penyuluh mengamati perubahan-perubahan perilaku tersebut dan diharapkan dapat diterapkan pada tindakan nyata di lapangan.

4. Tim penyuluh mengamati secara periodik peningkatan kualitas hidup masyarakat melalui pengukuran ketercapaian penggunaan BLT dana desa yang positif dan produktif.

5. Tim penyuluh mengamati hasil dari penyuluhan yang sudah dilakukan, dengan harapan serapan BLT dana desa yang digunakan untuk hal-hal positif dan produktif di masyarakat semakin meningkat.

\section{HASIL DAN PEMBAHASAN}

Pelaksanaan pengabdian masyarakat ini dilakukan di Aula Kantor Desa Ridan Permai Kecamatan Bangkinang Kota, Kabupaten Kampar, Provinsi Riau. Berikut lokasi sasaran tempat pengabdian dilaksanakan: 


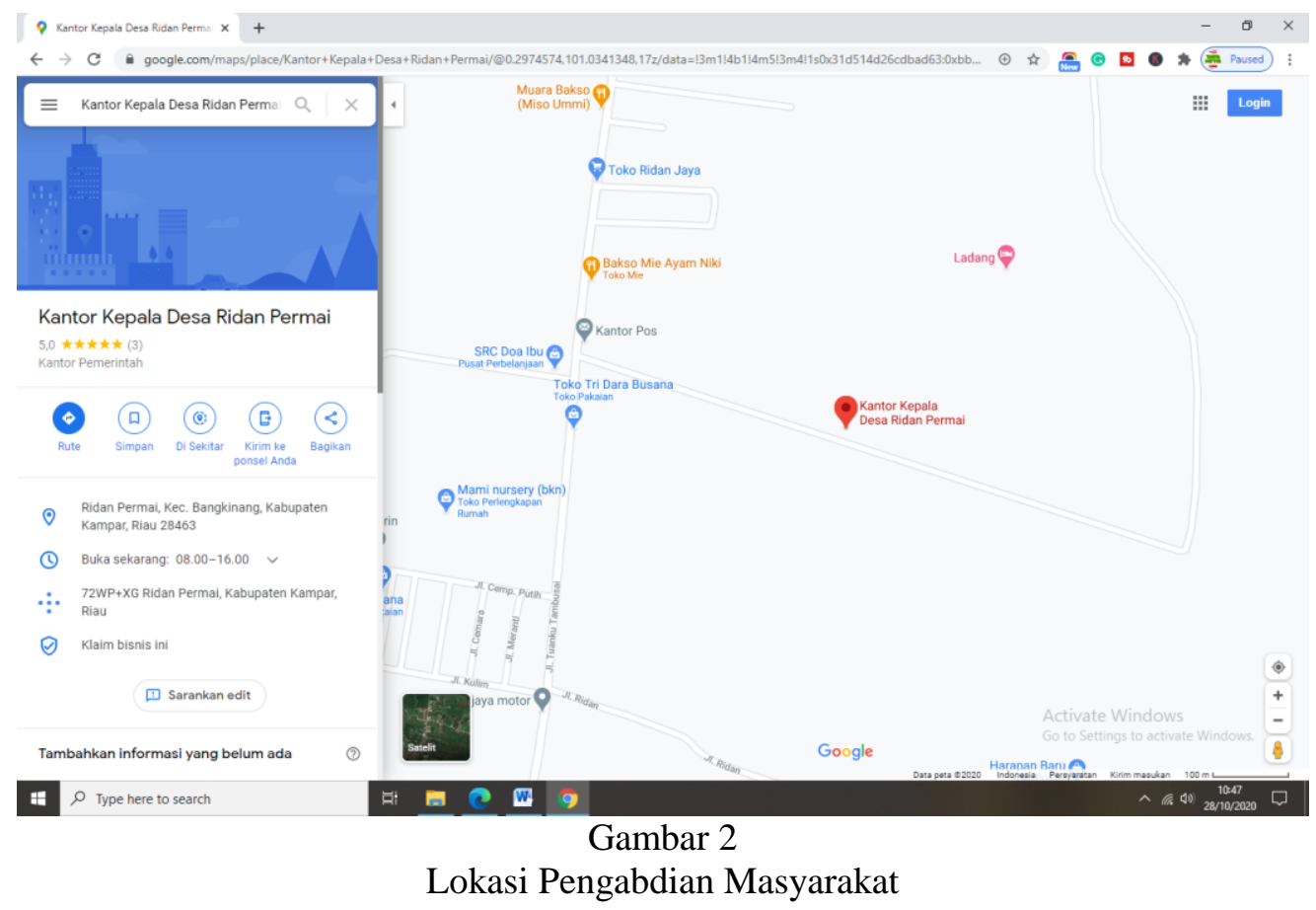

Pelaksanaan hasil penyuluhan dan musdeskus secara umum dapat dikatakan lancar dan sesuai dengan tahapan yang dijelaskan pada langkah-langkah pengabdian yang direncanakan sebelumnya. Prosedur pertama yang dilakukan oleh tim penyuluh adalah memberikan penyuluhan berupa pengetahuan akan pentingnya informasi terkini tentang kriteria dan peruntukan BLT dana desa tahun 2021. Kegiatan tersebut didokumentasikan pada Gambar 3 dibawah ini:

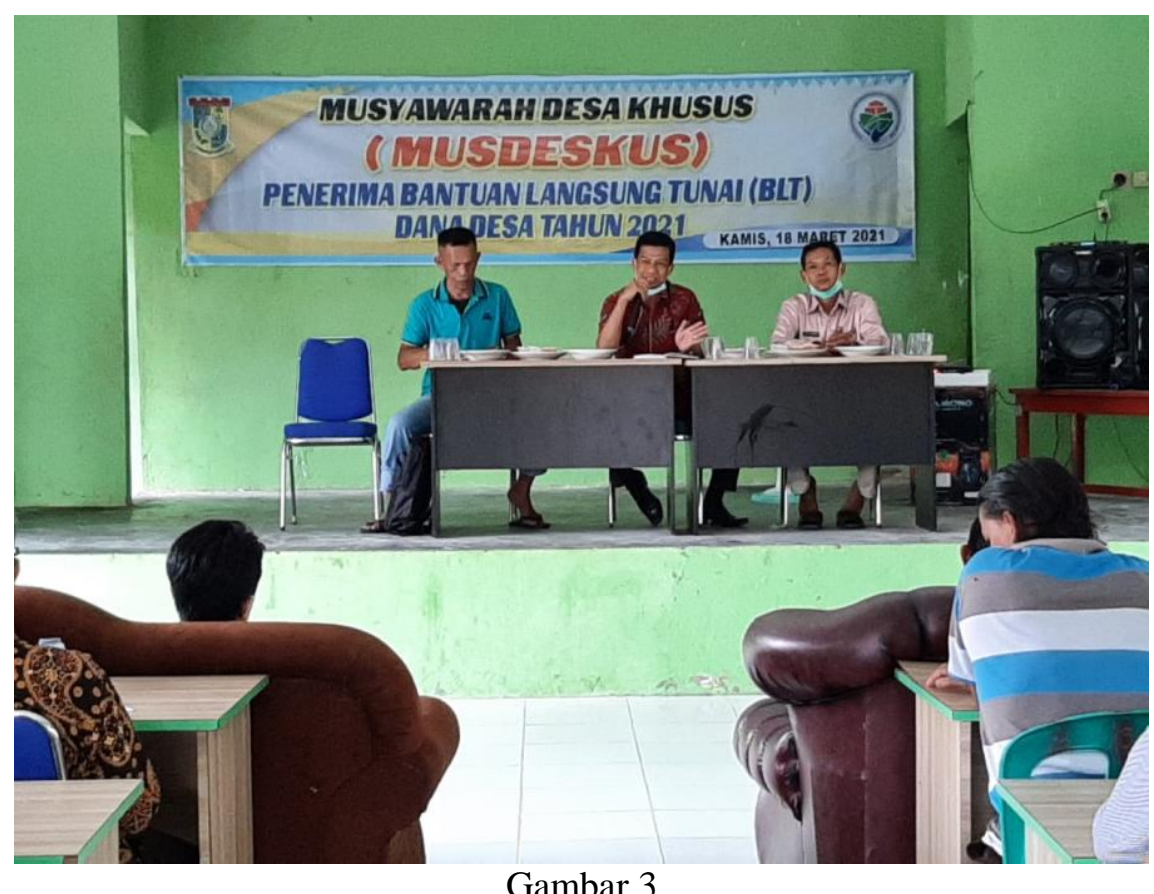

Pelaksanaan Penyuluhan dan Musdeskus Penerima BLT Dana Desa tahun 2021

Pada Gambar 3 diatas nampak bahwa masyarakat Desa Ridan Permai sangat antusias mengikuti penyuluhan dan musdeskus ini. Penyuluhan dan musdeskus ini tentu saja dihadiri oleh Kepala Desa Ridan Permai dan jajarannya. Aula desa yang ada cukup repserentatif untuk kegiatan ini dilakukan. Adanya jadwal dan tahapan yang jelas sehingga pelaksanaan penyuluhan dan musdeskus ini bisa berlangsung secara lancar dan terkendali. Antusiasme ini ditunjukkan warga 
dikarenakan selama ini mereka mendapatkan informasi yang berbeda satu sama lain dan tidak jelas sumbernya mengenai BLT dana desa tahun 2021.

Tahap kedua yang dilakukan oleh tim penyuluh adalah tim penyuluh memberikan kesempatan untuk bertanya, berdiskusi, dan bermusyawarah mengenai hal-hal yang menjadi harapan dan kendala yang dirasakan. Kegiatan tersebut didokumentasikan pada Gambar 4 dibawah ini:

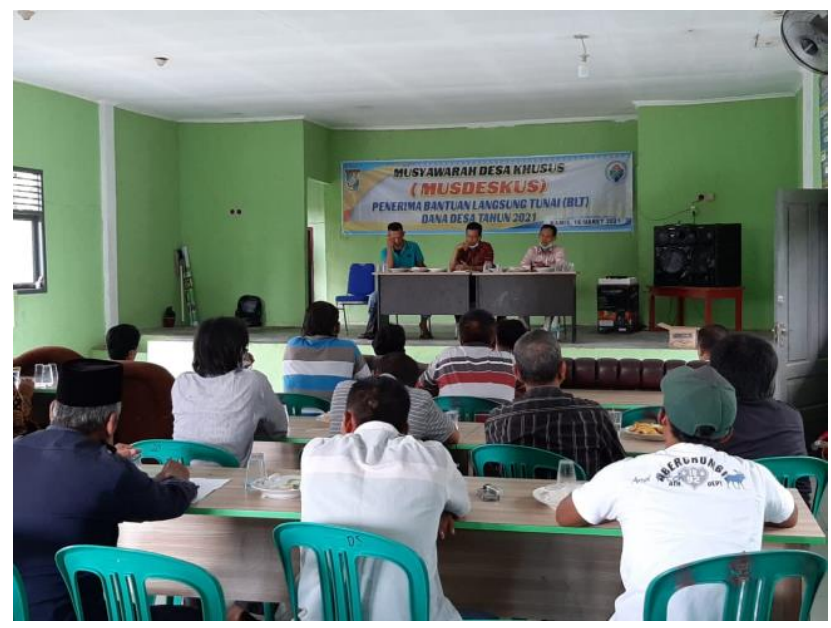

Gambar 4

Tanya Jawab, Diskusi, dan Musyawarah dalam Musdeskus penerima BLT Dana Desa Tahun 2021

Pada Gambar 4 di atas nampak bahwa masyarakat Desa Ridan Permai sangat antusias mengikuti penyuluhan dan musdeskus ini. Penyuluhan dan musdeskus ini tentu saja dihadiri oleh Kepala Desa Ridan Permai dan jajarannya. Pada pelaksanaan tanya jawab, diskusi, dan musyawarah dalam musdeskus ini dilakukan secara bertahap. Hal ini dilakukan agar tidak terjadi penumpukan pertanyaan warga yang menggantung dan agar penyuluhan dan musdeskus bisa berlangsung secara lancar.

Tahap ketiga adalah tim penyuluh memberikan contoh hasil sikap masyarakat yang sudah menggunakan BLT dana desa di tahun sebelumnya untuk sesuatu yang positif dan produktif. Contoh hasil salah satu warga masyarakat yang sudah menggunakan BLT dana desa di tahun sebelumnya untuk sesuatu yang positif dan produktif dapat dilihat pada Gambar 5 berikut:

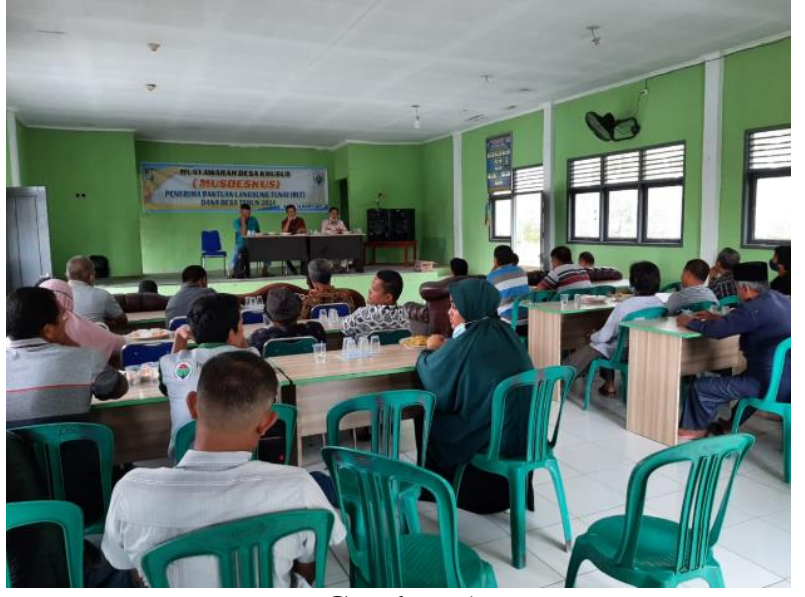

Gambar 5

Penerima BLT tahun Sebelumnya yang Positif dan Produktif

Dari penyuluhan dan musdeskus yang telah dilakukan, tim penyuluh mengamati perubahan perilaku yang diharapkan, yaitu semakin pahamnya masyarakat akan peruntukan BLT dana desa tahun 2021.Tim penyuluh juga mengamati perubahan-perubahan perilaku tersebut dan diharapkan dapat diterapkan pada tindakan nyata di lapangan. Kebiasaan lama yang tidak baik semakin berkurang dan digantikan dengan kebiasaan baru yang lebih baik dan lebih produktif. Untuk itu, 
perlu upaya yang cukup keras karena merubah kebiasaan memanglah tidak mudah dan memerlukan usaha yang maksimal.

Mekanisme penyaluran dan pemanfaatan BLT dana desapun rasanya harus ditata lebih baik lagi. Mekanisme mungkin bisa melibatkan Bumdes. Bumdes dipacu agar bisa memetakan sasaran masyarakat penerima BLT dana desa lebih tepat. Satu hal yang penting dalam pengelolaan Bumdes yaitu dibutuhkan suatu pengelolaan dan pelaporan yang transparan bagi pemerintah dan masyarakat, artinya, dasar pengelolaan harus serba transparan dan tercatat sehingga terdapat mekanisme chek and balance baik oleh pemerintahan desa maupun masyarakat. Untuk langkah ke depan sangat diperlukan sebuah penyusunan rencana-rencana pengembangan usaha. Contoh yang dapat diambil misalnya untuk penjualan produk-produk yang dipengaruhi oleh musim, seperti penjualan pakaian, sandal, sepatu, dan sejenisnya penting untuk selalu memperhatikan perubahan mode, sebab jika tidak dilakukan kemungkinan produknya tidak diminati oleh pasar, untuk itu diperlukan inovasi baru atau selalu mewaspadai perubahan dan perkembangan yang terjadi di masyarakat, hal tersebut sejalan dengan hasil pengabdian masyarakat yang dilakukan oleh (Febryani et al., 2018) yang mengungkapkan bahwa diperlukan inovasi dalam mengembangkan Bumdes agar lebih maju lagi.

Berdasarkan analisis yang telah dilakukan, terdapat indicator-indikator yang mendapat prioritas untuk ditingkatkan pengelolaannya adalah sarana dan prasarana, inovasi terhadap produksi yang dihasilkan, mengembangkan jaringan distribusi produk, melakukan pelatihan Sumber Daya Manusia (SDM) secara berkala, dan memiliki budaya organisasi. Selain itu dihasilkan gap atau kesenjangan antara kepentingan dengan kinerja menunjukan bahwa kinerja Bumdes saat ini agak kurang dari harapan yang diinginkan oleh pemerintah desa dan masyarakat. Hal tersebut juga diungkapkan oleh (Rahmawati, 2020) bahwa Bumdes harus terus dipacu oleh pemerintah desa dan warganya.

Bumdes dipandang sebagai paradigma pemberdayaan di desa. Paradigma pemberdayaan ekonomi rakyat sebenarnya bukan saja berupa tuntutan atas pembagian secara adil aset ekonomi, tetapi juga merupakan keniscayaan ideologis dengan semangat meruntuhkan dominasi-dominasi birokrasi dalam mengatur dan menentukan kehidupan rakyat (Majdi, M. et al., 2020). Gagasan pemberdayaan ekonomi rakyat menurut (Agunggunanto, E. et al., 2016) merupakan upaya mendorong dan melindungi tumbuh dan berkembangnya kekuatan ekonomi lokal dan penguasaan ilmu pengetahuan dan teknologi yang berbasiskan para kekuatan rakyat.

Dengan demikian, agar ekonomi masyarakat desa menjadi kuat maka diperlukan kerjasama, membangun kebersamaan dalam semua elemen yang ada di desa baik antara pemerintah desa dan masyarakat (Kirowati \& Setia, L., 2018). Adanya kerjasama dan kebersamaan yang erat dalam pengelolaan Bumdes mendapatkan manfaat berupa pemasukan pendapatan bagi desa dan juga masyarakat sehingga dapat menekan kemiskinan serta pengangguran dengan membuka peluang usaha dan bekerja bagi masyarakat desa (Endah, 2018) sehingga desa kedepannya menjadi desa mandiri.

Desa mandiri merupakan desa yang mampu memenuhi kebutuhannya dan apabila terdapat bantuan dari Pemerintah, bantuan tersebut hanya bersifat stimulus. Pembangunan desa mandiri meliputi kegiatan-kegiatan rencana pembangunan yang bersifat partisipatif, transparan, akuntabel, dan mendetail. Adapun strategi yang dapat dilakukan untuk mencapai desa mandiri tersebut dengan melakukan implementasi inovasi di setiap sendi lembaga usaha Bumdes (Nursetiawan, 2018). Ada tiga sektor yang menjadi fokus dalam usaha realisasi kemandirian sebuah desa, yakni: (a) potensi ekonomi; (b) potensi sosial; dan (c) potensi SDM. Potensi ekonomi sebagai bagian terpenting dalam usaha peningkatan taraf hidup masyarakat diperlukan inovasi usaha dalam pengelolaan Bumdes. Salah satunya dapat menerapkan teknologi informasi dalam usaha pengembangan usaha yang dilakukan oleh Bumdes (Ridlwan, 2014).

Pengelolaan Bumdes harus dijadikan sebagai landasan utama untuk membangun ekonomi pedesaan (Istanti \& Zuhroh, 2020). Keberadaannya seharusnya membawa perubahan yang signifikan di bidang ekonomi dan juga social. Oleh karena itu, Bumdes yang dikembangkan di 
desa sangat membutuhkan tenaga SDM yang professional sebagai motor penggerak untuk pengembangan dan pengelolaan Bumdes tersebut (Prawitno et al., 2019).

Tim penyuluh mengamati secara periodik peningkatan kualitas hidup masyarakat melalui pendampingan berkelanjutan secara bertahap dan pengecekan secara umum. Tim penyuluh mengamati hasil dari penyuluhan dan musdeskus yang sudah dilakukan, dengan harapan kesejahteraan masyarakat semakin meningkat. Sampai dengan artikel ini diterbitkan, kebiasaankebiasaan baru yang warga lakukan semakin membaik dan bisa menunjukkan arah yang jauh luas lagi.

\section{SIMPULAN}

Hasil pelaksanaan Penyuluhan Musdeskus penerima BLT Dana Desa Tahun 2021 dapat disimpulkan bahwa pengelola dana desa dapat memahami hubungan antara rencana jangka panjang dengan jangka pendek sehingga memudahkan petugas dalam menentukan anggaran untuk setiap aktivitas yang ada dalam rencana tersebut. Hasil musdeskus juga menunjukkan semakin bertambahnya pengetahuan dan pemahaman masyarakat mengenai kriteria masyarakat penerima BLT dan peruntukkannya.

\section{SARAN}

Saran-saran yang bisa diberikan diungkapkan sebagai berikut: pelaksanaan penyuluhan dan musdeskus ini sebaiknya dilakukan secara bertahap dengan memperhatikan jumlah masyarakat yang hadir. Perlu pembatasan jumlah masyarakat yang hadir dalam setiap pertemuan maksimal 20 orang agar penyuluhan dan musdeskus bisa diselenggarakan lebih kondusif dan masyarakat bisa fokus terhadap apa yang disampaikan.

\section{UCAPAN TERIMA KASIH}

Tim pengabdian kepada masyarakat mengucapkan terima kasih kepada Universitas Pahlawan Tuanku Tambusai dan Desa Ridan Permai yang telah memberi dukungan dana dan moril terhadap terlaksananya pengabdian masyarakat ini. Tim pengabdian kepada masyarakat juga mengucapkan terima kasih kepada Pengelola Community Development Journal yang telah memberi review dan masukan atas terbitnya artikel ini.

\section{DAFTAR PUSTAKA}

Agunggunanto, E., Y., Arianti, F., Kushartono, E., W., \& Darwanto. (2016). PENGEMBANGAN DESA MANDIRI MELALUI PENGELOLAAN BADAN USAHA MILIK DESA ( BUMDes ). JDEB, 13(1), 67-81.

Chrisanto, E. Y., Sari, R. Y., Hermawan, D., \& Andoko. (2020). PENYULUHAN PENTINGNYA PENCEGAHAN DAN PENGOBATAN PENYAKIT DIABETES MELLITUS GANG MAWAR KEMILING BANDAR LAMPUNG WILAYAH KERJA PUSKESMAS KEMILING BANDAR LAMPUNG. Jurnal Kreativitas Pengabdian Kepada Masyarakat (PKM), 3(1), 62-66.

Endah, K. (2018). MEWUJUDKAN KEMANDIRIAN DESA MELALUI PENGELOLAAN BADAN USAHA MILIK DESA. Jurnal Moderat, 4(4), 25-33.

Febryani, H., Nurmalia, R., Lesmana, I., M., I., Ulantari, N., K., W., Dewi, D., P., Y., P., \& Rizky, N. (2018). KEBERADAAN BADAN USAHA MILIK DESA (BUMDES) SEBAGAI PENGUATAN EKONOMI DESA ABIANTUWUNG. Jurnal Ilmiah Akutansi Dan Humaniora, 8(1), 95-103.

Istanti, E., \& Zuhroh, D. (2020). MEWUJUDKAN DESA MANDIRI UNTUK MENGEMBANGKAN BADAN USAHA MILIK DESA. Jurnal Pengabdian LPPM Untag Surabaya, 05(02), 137-141.

Kirowati, D., \& Setia, L., D. (2018). PENGEMBANGAN DESA MANDIRI MELALUI BUMDES DALAM MENINGKATKAN KESEJAHTERAAN MASYARAKAT DESA. Jurnal Aksi (Akutansi Dan Sistem Informasi), 1(1), 15-24.

Lestari, D., I., Mustafa, M., R., \& Anggionaldi, M. (2020). Workshop dan Bimbingan Teknis Tata Cara Perencanaan serta Penganggaran Aktivitas Penggunaan Dana Desa. Jurnal Pengabdian Pada Masyarakat, 5(4), 1015-1024. https://doi.org/10.30653/002.202054.391 
Majdi, M., Z., Susilawati, Muhammad, F., \& Nurhastuti. (2020). Peran Badan Usaha Milik Desa (Bumdes) Dalam Pemberdayaan Ekonomi Masyarakat Di Desa Mas-Mas Kecamatan Batukliang Utara Kabupaten Lombok Tengah. JPEK: Jurnal Pendidikan Ekonomi Dan Kewirausahaan, 4(2), 236-242. https://doi.org/10.29408/jpek.v4i2.2827

Nuraini. (2020). SOSIALISAI KESEHATAN TENTANG ISPA DAN PEMERIKSAAN FISIK DADA DAN THORAKS DI WILAYAH RW.02, KELURAHAN KEBON BESAR KECAMATAN BATUCEPER. Jurnal Kreativitas Pengabdian Kepada Masyarakat (PKM), $3(1), 80-86$.

Nursetiawan, I. (2018). STRATEGI PENGEMBANGAN DESA MANDIRI MELALUI INOVASI BUMDES IRFAN. Jurnal Pengabdian Masyarakat, 1(1), 72-81.

Prawitno, A., Rahmatullah, \& Safriadi. (2019). ANALISIS PERANAN BADAN USAHA MILIK DESA (BUM DESA) DALAM PENINGKATAN PENDAPATAN ASLI DESA DI KABUPATEN GOWA. Jurnal Ilmu Sosial Dan Ilmu Politik, 5(2), 50-60.

Rahmawati, E. (2020). ANALISIS PENGELOLAAN BADAN USAHA MILIK DESA (BUMDESA) DI KABUPATEN BANDUNG BARAT. Jurnal Pengabdian Masyarakat, 1(17), 1-13.

Ramadana, C., B., Ribawanto, H., \& Suwondo. (2010). Keberaadaan Badan Usaha Milik Desa (Bumdes) Sebagai Penguat Ekonomi Desa. Jurnal Administrasi Publik (JAP), 1(6), 10681076.

Ridlwan, Z. (2014). URGENSI BADAN USAHA MILIK DESA (BUMDES) DALAM PEMBANGUN PEREKONOMIAN DESA. Fiat Justisia Jurnal Ilmu Hukum, 8(3), 424-440.

Sularno, Witarsa, R., Fadhilaturrahmi, \& Rizal, M. S. (2020). PENYULUHAN PALAWIJA DESA RIDAN PERMAI UNTUK KETAHANAN PANGAN SAAT PANDEMI COVID 19. Communnity Development Journal, 1(2), 151-156.

Witarsa, R., Fadhilaturrahmi, \& Rizal, M. S. (2020). Pengaruh Asupan Nutrisi Shake Kacang Kedelai terhadap Skala Lemak Perut Guru-guru Sekolah Dasar di Bangkinang Kota Kabupaten Kampar. Jurnal Basicedu, 3(2), 524-532.

Witarsa, R., \& Mufarizuddin. (2020). PENYULUHAN PALAWIJA DESA RIDAN PERMAI UNTUK EKSISTENSI KEANEKARAGAMAN HAYATI SUMBER PANGAN. Community Development Journal, 1(1), 36-40. 